\title{
The FAMOUS climate model (versions XFXWB and XFHCC): description update to version XDBUA
}

\author{
R. S. Smith \\ NCAS-Climate, Dept. of Meteorology, University of Reading, UK \\ Correspondence to: R. S. Smith (r.s.smith@reading.ac.uk)
}

Received: 3 November 2011 - Published in Geosci. Model Dev. Discuss.: 22 November 2011

Revised: 15 February 2012 - Accepted: 17 February 2012 - Published: 24 February 2012

\begin{abstract}
FAMOUS is an ocean-atmosphere general circulation model of low resolution, based on version 4.5 of the UK MetOffice Unified Model. Here we update the model description to account for changes in the model as it is used in the CMIP5 EMIC model intercomparison project (EMICmip) and a number of other studies. Most of these changes correct errors found in the code. The EMICmip version of the model (XFXWB) has a better-conserved water budget and additional cooling in some high latitude areas, but otherwise has a similar climatology to previous versions of FAMOUS. A variant of XFXWB is also described, with changes to the dynamics at the top of the model which improve the model climatology (XFHCC).
\end{abstract}

\section{Introduction}

FAMOUS (FAst Met Office/UK Universities Simulator) is an Earth System Model (ESM) derived from the Hadley Centre coupled model version 3 (HadCM3) (Gordon et al., 2000), a configuration of the UK Met Office Unified Model. Using approximately half the spatial resolution of HadCM3 and a tenth of its computational resources, FAMOUS can currently simulate $\sim 250 \mathrm{yr}$ in a day on 8 cores of a multi-core system, making GCM-complexity millennial-scale transient runs and large ensembles feasible. FAMOUS has been systematically tuned to reproduce both the equilibrium climate and climate sensitivity of HadCM3 (Jones et al. 2005; Smith et al. 2008, SOG08 hereafter).

Versions of FAMOUS are denoted by their Unified Model job codes - the version in Jones et al. (2005) was ADTAN, and SOG08 described version XDBUA. Following the publication of SOG08, use of the model highlighted a systematic instability under certain climate forcings, and a num- ber of errors were found in the model code. These issues have been addressed, and here we describe the resulting version XFXWB, which was used in Smith and Gregory (2012) and contributed to the EMICmip (www.climate.uvic. ca/EMICAR5) model intercomparison project. We also describe version XFHCC, a variant of XFXWB with a different solution to the instability problems seen in XDBUA. We update the model description given in SOG08, outlining only the changes to the model code and climatology. This update paper assumes familiarity with the material in SOG08; the basic material therein will not be repeated.

\section{Technical changes}

\subsection{Stratospheric winds}

The vertical resolution of the atmosphere model in FAMOUS is largely responsible for biasses in both heating and winds around and above the poorly-resolved tropopause (see e.g. Fig. 5 in SOG08). In particular, the top-level winds in XDBUA are unrealistically fast, and have been found to be the root cause of instability problems; simulations of glacial climates with XDBUA have been found to be particularly unstable (Gregoire et al., 2011).

Two solutions to this issue have been implemented. The simplest one is to simply cap the top-level winds at the speed above which the model becomes unstable, and this is what has been done in XFXWB. This does not improve the realism of the upper levels of FAMOUS, but it does solve the instability problem, and allows for a model with the well-understood climatology of XDBUA to be applied to glacial climate studies. The cap only takes effect at the point at which the model would otherwise crash, so does not appear to have had any impact on the preindustrial control climate of FAMOUS. 
A scientifically more satisfactory solution involves introducing friction to the top levels of the model to slow the winds to more realistic speeds. This is the approach taken in XFHCC. It seems likely that the low resolution of FAMOUS prevents the gravity wave drag parameterisation from working as it does in HadCM3, so another mechanism is required to remove energy from the top-level flow. Simple Rayleigh friction is added to the top three levels of the model, with timescales of (descending from the model top) 15, 30 and 60 days, respectively. These values were taken from those used in the IGCM (Forster et al., 2000), an intermediate complexity model of similar resolution that employs this parameterisation, and found to produce good results. The simple cap on top-level wind speeds is not required in FAMOUS if this frictional parameterisation is used in the model.

The introduction of top-level friction to the model also removes the instability problem from XFHCC, but it also changes the surface climate significantly (see Sect. 3.2). The atmosphere in the Unified Model is a grid-point model, with Fourier filtering routines to smooth small-scale variability that the grid is unable to represent. The unrealistically fast top-level winds of previous versions of FAMOUS led to the over-use of these filtering routines throughout the model, damping mid-latitude variability and atmospheric energy transport in the control climate. Furthermore, it appears that changes in the extreme top-level winds dominate the dynamical response to $\mathrm{CO}_{2}$-forced climate change in previous versions of FAMOUS, producing changes in wind patterns at odds with those found in the majority of climate models. Introducing friction in the top-level of FAMOUS thus has direct effects throughout the model. To take best practical advantage of this new parameterisation would require retuning other parameters in the model - ozone, and sea-ice albedo, for instance (see SOG08). This retuning is being done in conjunction with other major changes to the land surface model in FAMOUS, and will be described in a forthcoming paper. In the second half of this paper, the physical impact of the introduction of top-level friction alone will be described.

\subsection{Snow overlying coastal sea-ice}

One of the primary differences between FAMOUS and its parent model HadCM3 is the use of coastal tiling in FAMOUS. This mitigates the impact of FAMOUS's lower resolution on the land-sea interface by allowing coastal gridboxes in the atmosphere to see boundary conditions for land and sea simultaneously. The land model in XDBUA, however, only contained one snow-depth field. This meant that, during the ocean-atmosphere coupling step, snow lying in the land fraction of coastal gridboxes was overwritten by the field from the ocean fraction which held snow lying on sea-ice. Landbased coastal snow was thus lost from the model at the end of every day, resulting in not only a non-conservation of water in the model but also erroneous temperature and albedo effects.
A separate prognostic field for sea-ice based snow has now been implemented. The primary effect of this has been to cool coastal regions of the model during winter: the majority of the change apparent in Fig. 1 is due to the correction of this error.

\subsection{Ocean sensible/latent heat fluxes}

During the calculation of surface turbulence over the ocean, the gridbox-mean sensible and latent heat fluxes are erroneously interchanged. The impact of this error appears to be limited to boundary layer stability calculations that affect convection in the model, as the gridbox-means are calculated anew in the next subroutine. The resolution of this error does not appear to have had a significant impact on the preindustrial control climate of FAMOUS.

\subsection{Ocean penetration of solar radiation}

FAMOUS contains a version of the ocean biogeochemistry model HadOCC (Palmer and Totterdell, 2001), which some users choose to disable for reasons of computational efficiency. The version of HadOCC used in FAMOUS contains routines for altering the sub-surface penetration of solar radiation in the ocean according to plankton levels. In XDBUA, the code was written such that simply disabling HadOCC through FAMOUS's user interface left these routines in place, with the resulting modifications of solar penetration becoming undefined. Correcting this error has not been shown to produce significant effects in the climate of FAMOUS, but its impact is compiler and runtime dependent so is difficult to assess.

\subsection{Minor issues}

The version of HadOCC in XDBUA contained an undocumented code change, whereby the diagnostic of zooplankton production in fact shows calcite export instead. This has now been corrected. Code for the third-order advection scheme for the biogeochemical tracers in HadOCC also clashes with the diagnostics of vertical velocity within the ocean, such that detailed energy budgets calculated from the model diagnostics no longer close. This issue has not yet been fixed, although the diagnostic of ocean temperature tendencies due to advection have been made more accurate.

In addition, FAMOUS now contains a number of minor ocean code rewrites, designed to ensure consistent code behaviour across different compilers. The inclusion of this code has not been shown to affect the climate of FAMOUS.

\section{Climatologies}

NetCDF files of climatological data for the control simulations of XFXWB and XFHCC are provided in the supplementary material to this article. 

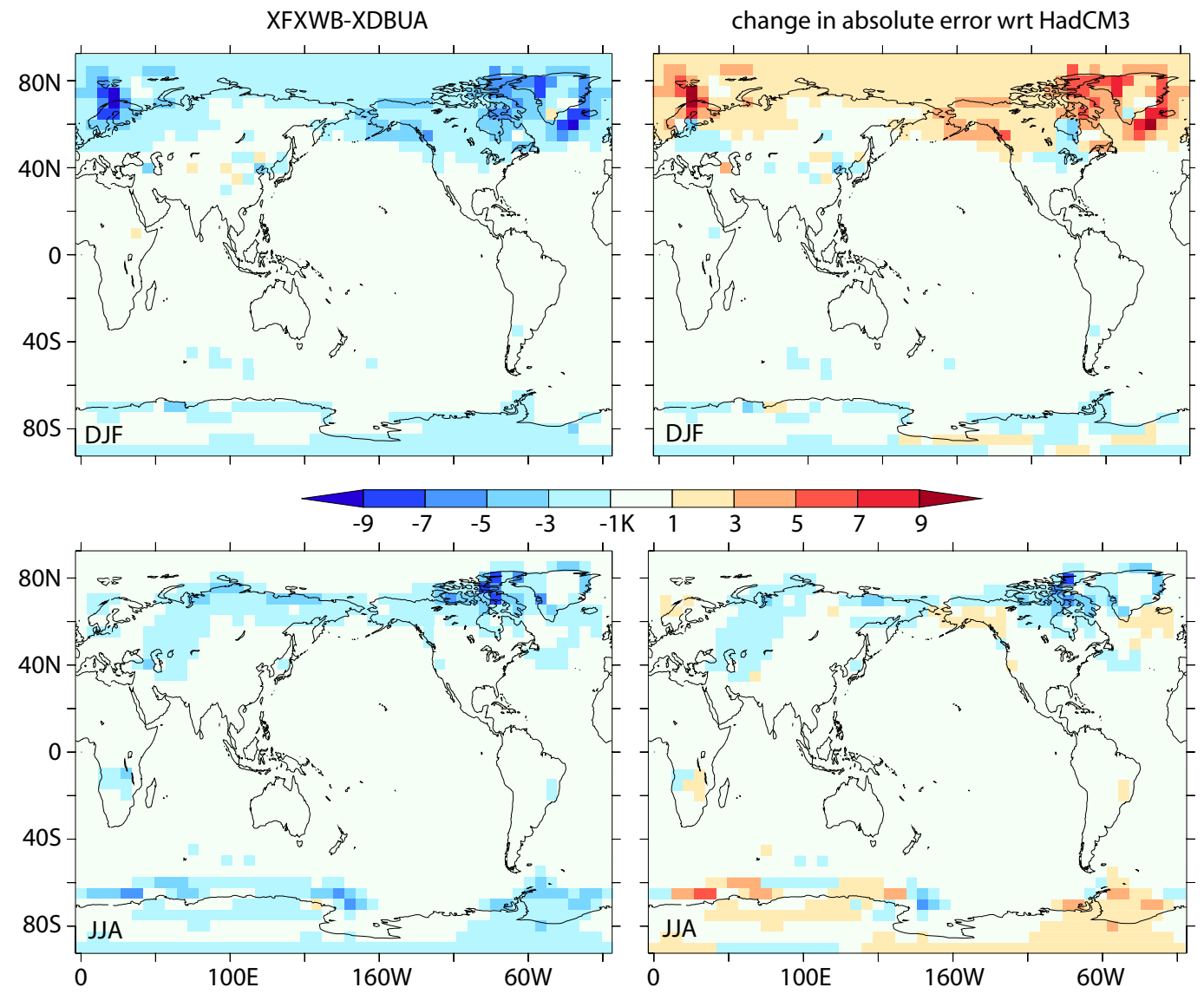

Fig. 1. Difference in seasonal surface temperature. Left: XFXWB-XDBUA; right: change in magnitude of error with respect to HadCM3; top: DJF; below: JJA.

\subsection{XFXWB climatology}

A series of standard experiments were conducted with XFXWB, including a preindustrial control run and a number of idealised $\mathrm{CO}_{2}$ forcing experiments. These have been submitted to the EMICmip model intercomparison project (www.climate.uvic.ca/EMICAR5). The setup of the preindustrial control run of XFXWB differs from that of XDBUA in a number of ways. XDBUA used a somewhat adhoc collection of "modern" boundary conditions, with an atmospheric $p \mathrm{CO}_{2}$ of 290 ppmv but orbital parameters appropriate for $2000 \mathrm{CE}$. XFXWB, rather more consistently, uses an atmospheric $p \mathrm{CO}_{2}$ of $282 \mathrm{ppmv}$, and orbital parameters from $1850 \mathrm{CE}$. The value of the solar constant is also slightly different, consistent with historical records. The imposed iceberg calving field (see SOG08 for details) has also been slightly recalibrated for this run to better conserve global ocean salinity. XFXWB was run on $5000 \mathrm{yr}$ from the end of the $6000 \mathrm{yr}$ control run of XDBUA. At the end of the spinup, all surface fields in XFXWB are in equilibrium, with a drift of $0.003{ }^{\circ} \mathrm{C}_{\text {century }}{ }^{-1}$ in bottom ocean temperatures, and a

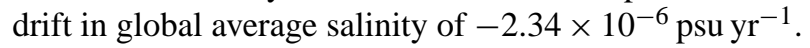

The main difference between XDBUA and XFXWB lies in the surface temperatures (Fig. 1, left). This is mostly driven by the increase in coastal snow cover that results from the fix described in Sect. 2.2. Expressed as radiative forcings, the changes in solar and greenhouse gas boundary conditions noted above would be expected to result in a global, annual average cooling of around $0.1^{\circ} \mathrm{C}$, although the seasonal changes in orbital forcing might, in fact, be expected to produce a net warming of around $1^{\circ} \mathrm{C}$ over high latitudes in winter and spring. Compared to XDBUA, XFXWB has cooling in December, January and February (DJF) of up to $2{ }^{\circ} \mathrm{C}$ on Antarctica and in the Arctic, with additional patches of enhanced cooling around the coasts, especially in the North Pacific. In June, July and August (JJA) there is a small cooling over the Northern Hemisphere land masses. There are small (generally $<0.1$ ) increases in annual mean sea-ice fraction resulting from the high latitude cooling.

Although the differences between XFXWB and XDBUA are almost entirely in one direction, the picture with regard to how FAMOUS deviates from HadCM3 is mixed (Fig. 1, right). In DJF in XFXWB, the Northern Hemisphere cooling increases the size of the error with respect to HadCM3, whilst 
XFXWB-NCEP

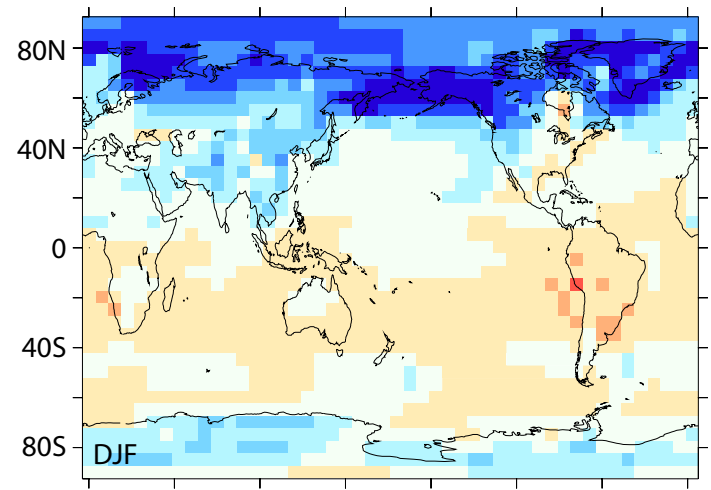

XFHCC-NCEP

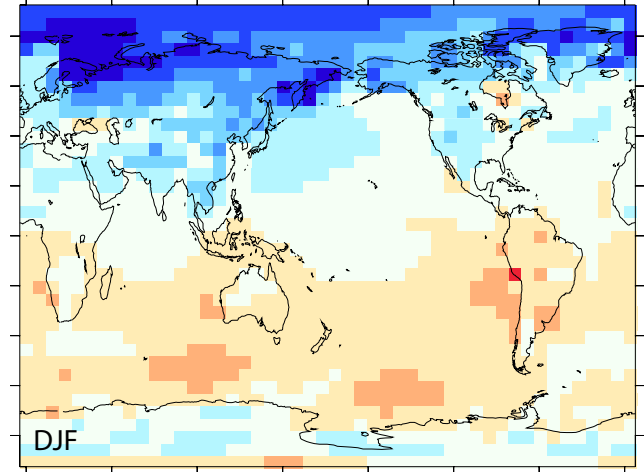

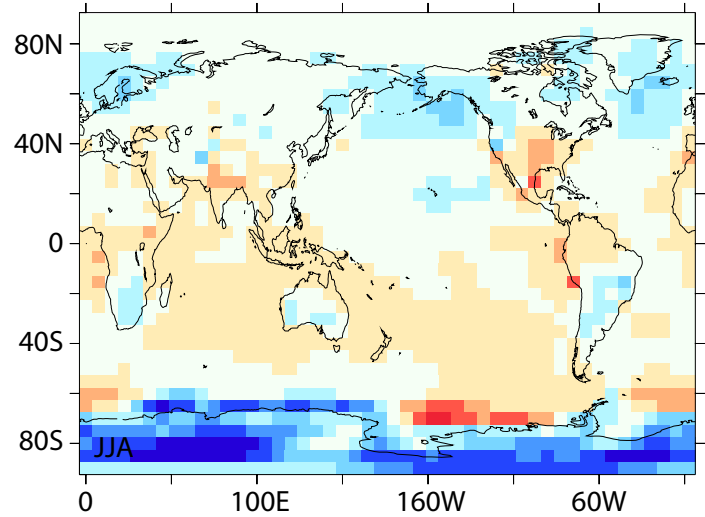

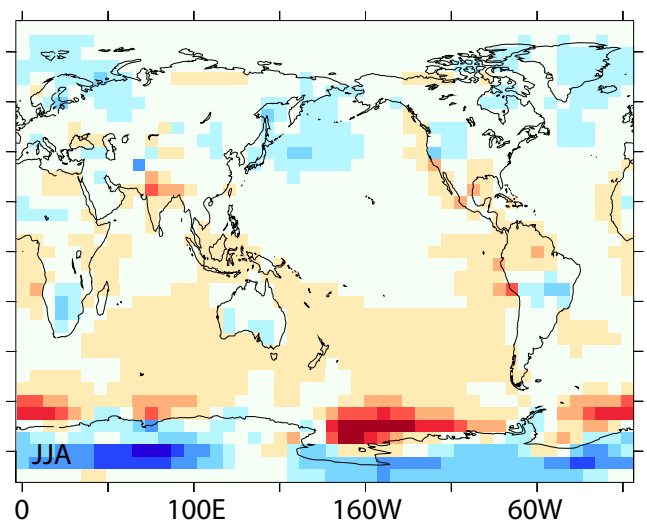

Fig. 2. Errors in seasonal surface temperature with respect to the NCEP reanalysis (Kalnay et al., 1996). Left: XFXWB-NCEP; right: XFHCC-NCEP; top: DJF; below: JJA.

over Antarctica in DJF and the Northern Hemisphere in JJA the cooling in XFXWB tends to reduce the error. The ArcsinMielke skill scores with respect to HadCM3 (a metric of how well both the magnitude and pattern of two different fields match, see Jones et al. (2005) for details) for the northern high latitude (poleward of $45^{\circ} \mathrm{N}$ ) surface temperature patterns which dominate the bias in FAMOUS are correspondingly a little lower for XFXWB than XDBUA in DJF and the annual mean, although still higher than in ADTAN, the original version of FAMOUS (Table 1). FAMOUS's most notable problem remains a high latitude winter cold bias (Fig. 2, left), compounded by an over-estimate of winter sea-ice coverage in the Northern Hemisphere.

In experiments with elevated levels of atmospheric $p \mathrm{CO}_{2}$ (not shown), XFXWB has been found to display a slow longterm surface temperature drift (around $0.2{ }^{\circ} \mathrm{C}$ per century). This makes defining a single number for its climate sensitivity hard, but taken over the first $150 \mathrm{yr}$ of more rapid adjustment to an instantaneous increase to four times preindustrial atmospheric $\mathrm{CO}_{2}$, XFXWB has a slightly lower climate feedback parameter (Gregory et al., 2004) than XDBUA of $0.91 \pm 0.05 \mathrm{~W} \mathrm{~m}^{-2} \mathrm{~K}^{-1}$, closer to the value of ADTAN than HadCM3.
Table 1. Arcsin-Mielke skill scores for surface temperature poleward of $45^{\circ} \mathrm{N}$ with respect to HadCM3 in different versions of FAMOUS. Potential scores range from 1 to -1 , with 1 denoting a perfect match between fields, 0 implying no correlation at all and -1 perfect anti-correlation.

\begin{tabular}{lcccc}
\hline & ADTAN & XDBUA & XFXWB & XFHCC \\
\hline DJF & 0.60 & 0.70 & 0.63 & 0.79 \\
JJA & 0.79 & 0.76 & 0.80 & 0.84 \\
Annual & 0.66 & 0.77 & 0.72 & 0.85 \\
\hline
\end{tabular}

\subsection{XFHCC climatology}

The experiment described is setup essentially as for XFXWB, with the only significant difference being the addition of Rayleigh friction in the top three levels of the model and the lack of a cap on the top-level wind speeds. The iceberg calving field of XDBUA was used in XFHCC, as this was found to be balance the global water budget better than the field calculated for XFXWB, but this has no effect on the results shown here. The run is initialised from year 5000 of 

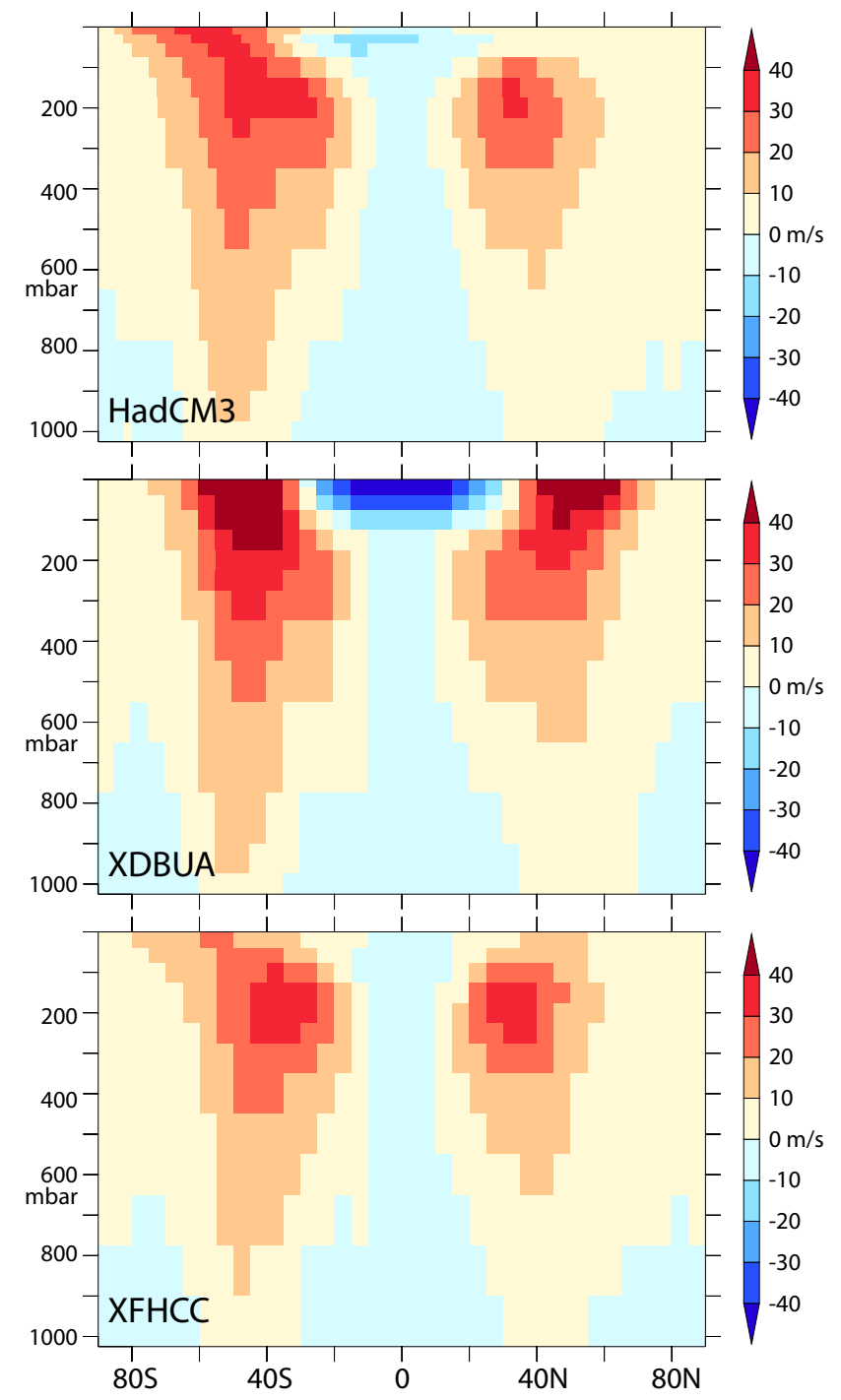

Fig. 3. Annual, zonal average zonal winds. Top: HadCM3; middle: XDBUA; bottom: XFHCC.

XFXWB, and run for $1000 \mathrm{yr}$. Rather than providing a new control climate for FAMOUS, this experiment is designed to show the impact of the top-level friction alone. A fully retuned version of the model, combining the top-level friction with a number of other major changes to the science in FAMOUS, will be described in a forthcoming paper.

This brings the vertical distribution of zonal winds into much better agreement with both observations and higher resolution models (Fig. 3). The vertical temperature profile in the model is also improved, following the thermal wind relation.

The immediate effect of the introduction of top-level friction in FAMOUS is the improvement in the general shape of the zonal winds in XFHCC (Fig. 3). Maxima in the jets move to their correct location and magnitude at around $30 \mathrm{~m} \mathrm{~s}^{-1}$

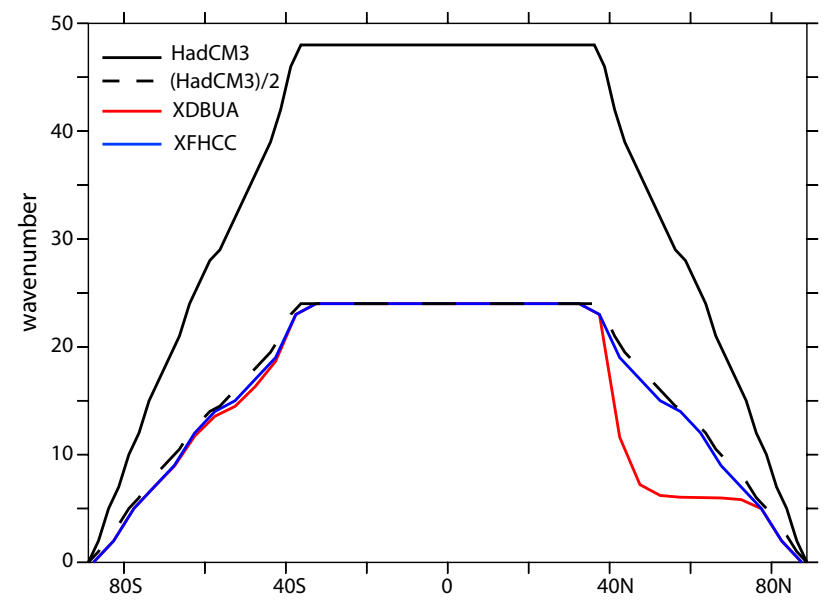

Fig. 4. Maximum wavenumber allowed by the Fourier filtering in DJF. Black, solid: HadCM3; black, dashed: HadCM3 data divided by 2 , a profile that might be expected of a model with half the resolution of HadCM3; green: XDBUA; blue: XFHCC.

at $200 \mathrm{mbar}$, rather than increasing to $\pm 70 \mathrm{~m} \mathrm{~s}^{-1}$ or more in the top level of the model. Vertical temperature profiles at higher latitudes now suggest a more realistic tropopause height (see Fig. 5, SOG08) and imply that more realistic levels of ozone than the low values specified in XDBUA could now be used to improve stratospheric temperature profiles. The reduction in strength of the jets however reduces their vertical extent as well, leading to weaker zonal winds at the surface in XFHCC. The most immediate impact of this is a reduction in the strength of the Antarctic Circumpolar Current (ACC), from around $70 \mathrm{~Sv}$ to around $50 \mathrm{~Sv}$, which is at the lower end of the range of values in the coupled model intercomparison database of Meehl et al. (2007).

The slowing in top-level winds reduces the impact of the Fourier filtering routines in the model that are intended to remove subgridscale variability at high latitudes. These routines are clearly over-active in XDBUA, cutting out features with wavenumbers above 6 poleward of $50^{\circ} \mathrm{N}$ in DJF (Fig. 4). By contrast, filtering in XFHCC follows a profile more in line with that expected for a model with FAMOUS's resolution, allowing wavenumbers up to around 15 at $50^{\circ} \mathrm{N}$ in DJF.

The increase in mid-latitude variability affects atmospheric energy transport (Fig. 6), bringing it into closer agreement with that found in HadCM3 and resulting in significant surface temperatures differences between XFHCC and XFXWB (Fig. 5, left). High latitude surface temperatures are generally higher in XFHCC, especially in the winter hemisphere, with reductions in temperature at lower latitudes. High latitude temperature changes are accentuated by reductions in sea-ice, whose extent FAMOUS generally overestimates. The apparent exception to this pattern is the cooling over Europe and eastern Russia in DJF which results 

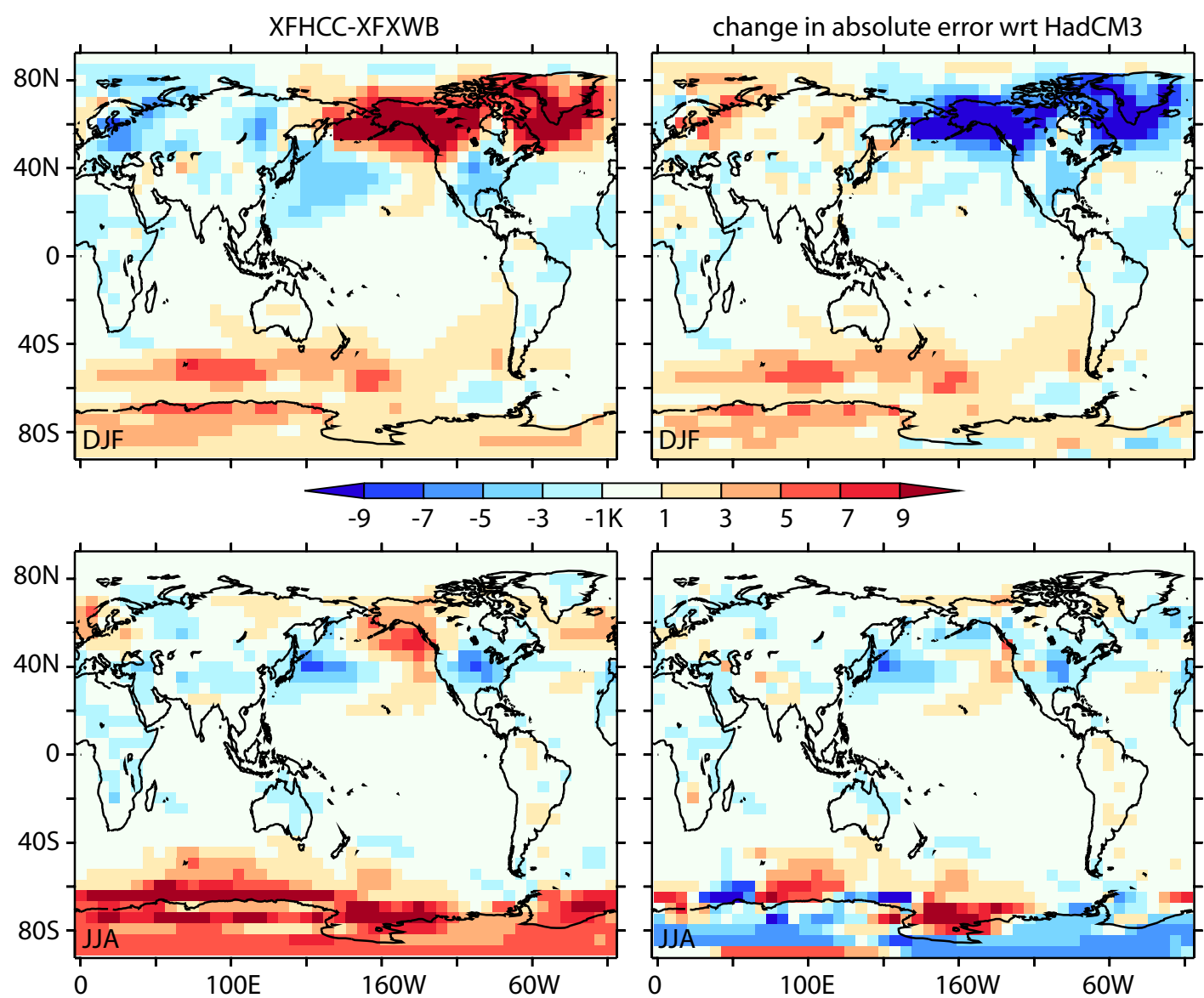

Fig. 5. Difference in seasonal surface temperature. Left: XFHCC-XFXWB; right: change in magnitude of error with respect to HadCM3; top: DJF; below: JJA.

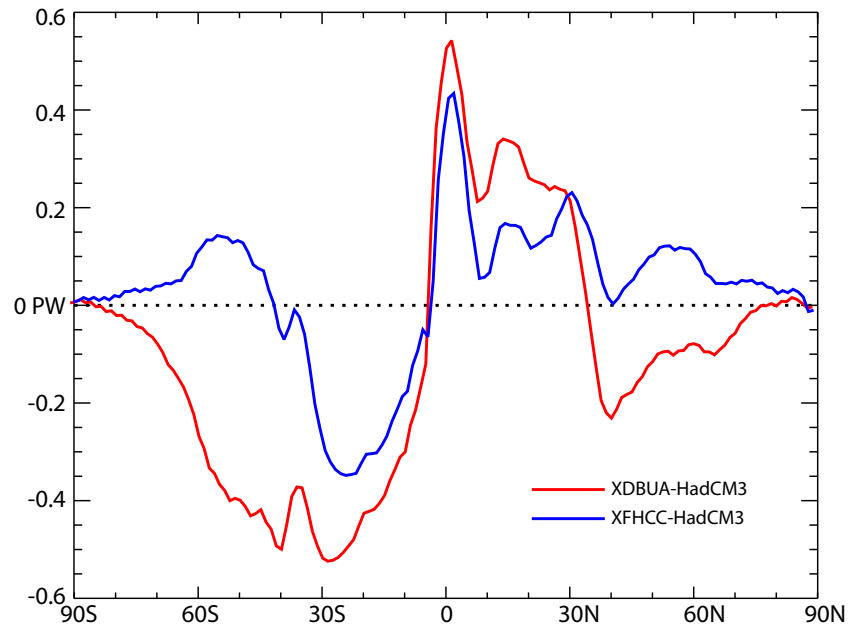

Fig. 6. Difference in magnitude of the annual average atmospheric energy transport between FAMOUS and HadCM3. Black: XDBUA-HadCM3; red: XFHCC-HadCM3. from an anomalous cyclonic circulation which brings Arctic air down over eastern Europe, with a local surface albedo effect due to enhanced snow cover.

The DJF Northern Hemisphere warming in XFHCC significantly reduces the size of the error with respect to HadCM3, as does the DJF cooling over North America (Fig. 5, right). Other DJF changes generally increase the error, especially the cooling over Russia, such that there is almost no global average change in DJF error between XFXWB and XFHCC. Overall, the DJF error pattern with respect to HadCM3 in XFHCC is much more even than XFXWB, being less biassed towards anomalous North $\mathrm{Pa}$ cific and North Atlantic cooling. Nearly all JJA changes in surface temperature in XFHCC reduce the size of the error, although by smaller amounts. The Arcsin-Mielke skill scores with respect to HadCM3 for the northern high latitude temperature patterns are significantly higher in XFHCC than in any previous version of FAMOUS (Table 1), emphasising this improvement. XFHCC thus has an improved winter cold bias (Fig. 2, right) compared to other versions of FAMOUS, although this problem is not totally removed. 

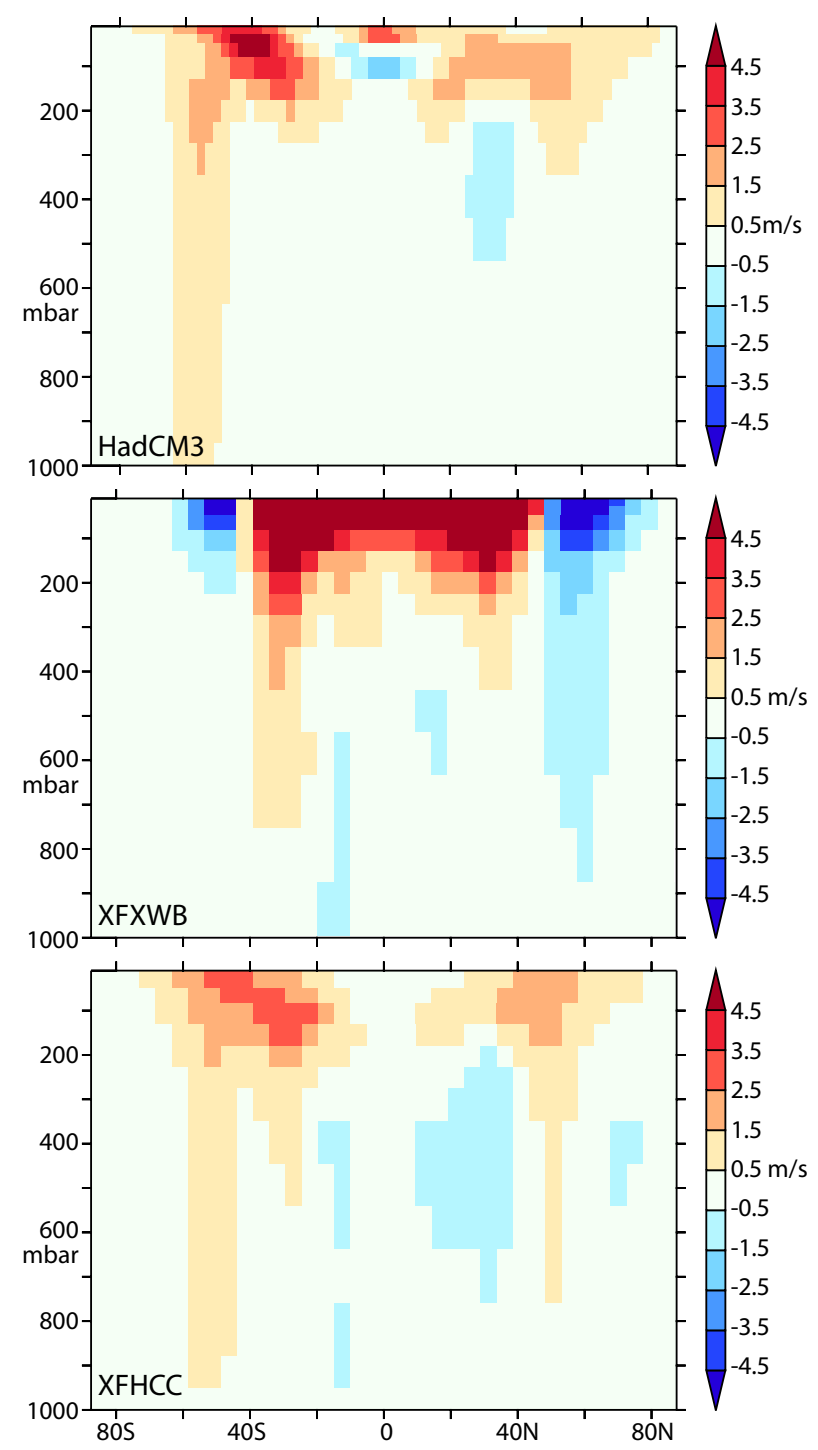

Fig. 7. Changes in annual average, zonal average winds at $2 \times \mathrm{CO}_{2}$ in $1 \% \mathrm{CO}_{2}$ increase runs. Top: HadCM3; middle: XFXWB; bottom: XFHCC.

The Atlantic meridional overturning circulation also changes between XFXWB and XFHCC, with both the maximum and the overall shape of the overturning becoming significantly deeper, extending to the bottom and excluding Antarctic bottom water (AABW) from the Atlantic in XFXWB. It is not clear whether this results from the changes in surface temperature and ice coverage in the North Atlantic, a response to the weaker ACC (and likely weaker AABW formation, which is well correlated with the strength of the ACC; Gent et al., 2001), or some combination of these and other climate feedbacks.

Simulations with elevated levels of atmospheric $\mathrm{CO}_{2}$ have also been conducted with XFHCC. These do not appear to show the same long-term drift as in XFXWB, and are slightly less sensitive, with a climate feedback parameter that is much the same as XDBUA, at $1.10 \pm 0.05 \mathrm{~W} \mathrm{~m}^{-2} \mathrm{~K}^{-1}$. Changes in the precipitation fields under $\mathrm{CO}_{2}$ forcing are very similar in XFXWB and XFHCC. In such climate simulations, most models show a southward shift and intensification of Southern Ocean westerly winds (Wang et al., 2011). To compare with HadCM3 data, atmospheric $\mathrm{CO}_{2}$ in FAMOUS was increased at $1 \%$ a year until twice the pre-industrial value of $\mathrm{CO}_{2}$ was reached. In this experiment, XFXWB shows a weakening of the winds over the Southern Ocean. XFHCC does produce some intensification of Southern Ocean westerlies under this atmospheric $\mathrm{CO}_{2}$ forcing, which can be clearly traced back to the response of the high-altitude winds (Fig. 7), which is no longer dominated by the unrealistically high winds in the top level of XFXWB.

\section{Summary and outlook}

Changes to the formulation of FAMOUS since version XDBUA have been described. Despite a number of non-trivial technical improvements to the code, version XFXWB has a climatology that differs little from XDBUA, the main changes being a coastal cooling at high latitudes and a significant increase in model stability. Version XFHCC contains an additional improvement to the parameterisation of high-altitude winds that leads to a model climatology that is much improved in several other respects. NetCDF files of climatological data for the control simulations of XFXWB and XFHCC are provided in the supplementary material to this article.

All currently described versions of FAMOUS (ADTAN, XDBUA, XFXWB and XFHCC) employ the MOSES1 land surface scheme (Cox et al., 1999) as used in HadCM3. A new version of FAMOUS, containing the MOSES2.2 scheme (Essery et al., 2003), is currently being tuned. This version is capable of a simple closed carbon cycle and dynamic vegetation, as well as containing all the improvements described here and a more realistic sea-ice model, and will be described in a forthcoming publication. This new version of FAMOUS is also under further development to allow for subgridscale coupling of MOSES2.2 to the Glimmer community ice-sheet model, improving on the simple annual positive-degree-day coupling currently used for icesheet mass balance in Glimmer. More information on the use and development of FAMOUS can be found on the website at http://www.famous.ac.uk.

\section{Supplementary material related to this article is available online at: http://www.geosci-model-dev.net/5/269/2012/ gmd-5-269-2012-supplement.zip.}


Acknowledgements. I would like to acknowledge the support of Annette Osprey, Simon Wilson and other members of the NCAS Computer Modelling Support team in support of FAMOUS. Discussions with the community of FAMOUS users, notably Jonathan Gregory ${ }^{1,2}$ and Manoj Joshi ${ }^{1}$ of NCAS-Climate ${ }^{1}$ and the UK Met Office ${ }^{2}$, and members of the BRIDGE group in the Geography Department of the University of Bristol, contribute greatly to the ongoing development of the model. XFXWB was integrated on HECToR, the UK National Supercomputing resource. We would also like to thank Chris Jones ${ }^{2}$ and the UK Met Office for the original Unified Model code used in FAMOUS, and Hugo Lambert ${ }^{2}$, who contributed improvements to the ocean code. NCEP Reanalysis data provided by the NOAA/OAR/ESRL PSD, Boulder, Colorado, USA, from their Web site at http://www.esrl.noaa.gov/psd. This paper was improved thanks to comments by Chris Jones and an anonymous reviewer.

Edited by: D. Lunt

\section{References}

Cox, P. M., Betts, R. A., Bunton, C. B., Essery, R. L. H., Rowntree, P. R., and Smith, J.: The impact of new land surface physics on the GCM simulation of climate and climate sensitivity, Clim. Dynam., 15, 183-203, 1999.

Essery, R. L. H., Best, M. J., Betts, R. A., Cox, P. M., and Taylor, C. M.: Explicit representation of subgrid heterogeneity in a GCM land-surface scheme, J. Hydrometeorol., 4, 530-543, 2003.

Forster, P. d. F., Blackburn, M., Glover, R., and Shine, K.: An examination of climate sensitivity for idealised climate change experiments in an intermediate general circulation model, Clim. Dynam., 16, 833-849, 2000.

Gent, P., Large, W., and Bryan, F.: What sets the mean transport through the Drake Passage?, J. Geophys. Res., 106, 2693-2712, 2001.

Gordon, C., Cooper, C., Senior, C. A., Banks, H., Gregory, J. M., Johns, T. C., Mitchell, J. F. B., and Wood, R. A.: The simulation of SST, sea ice extents and ocean heat transports in a version of the Hadley Centre coupled model without flux adjustments, Clim. Dynam., 16, 147-168, 2000.
Gregoire, L. J., Valdes, J. P., Payne, A. J., and Kahana, R.: Optimal tuning of a GCM using modern and glacial constraints, Clim. Dynam., 37, 705-719, 2011.

Gregory, J. M., Ingram, W. J., Palmer, M. A., Jones, G. S., Stott, P. A., Thorpe, R. B., Lowe, J. A., Johns, T. C., and Williams, K. D.: A new method for diagnosing radiative forcing and climate sensitivity, Geophys. Res. Lett., 31, L03205, doi:10.1029/2003g1018747, 2004.

Jones, C., Gregory, J., Thorpe, R., Cox, P., Murphy, J., Sexton, D., and Valdes, P.: Systematic optimisation and climate simulations of FAMOUS, a fast version of HadCM3, Clim. Dynam., 25, 189204, 2005.

Kalnay, E., Kanamitsu, M., Kistler, R., Collins, W., Deaven, D., Gandin, L., Iredell, M., Saha, S., White, G., Woollen, J., Zhu, Y., Chelliah, M., Ebisuzaki, W., Higgins, W., Janowiak, J., Mo, K. C., Ropelewski, C., Wang, J., Leetmaa, A., Reynolds, R., Jenne, R., and Joseph, D.: The NCEP/NCAR 40-Year Reanalysis Project, Bull. Am. Meteorol. Soc., 77, 437-471, 1996.

Meehl, G. A., Covey, C., Delworth, T., Latif, M., McAveney, B., Mitchell, J. F. B., Stouffer, R. J., and Taylor, K. E.: The WCRP CMIP3 multi-model dataset: A new era in climate change research, Bull. Am. Meteorol. Soc., 88, 1383-1394, 2007.

Palmer, J. R. and Totterdell, I. J.: Production and export in a global ocean ecosystem model, Deep-Sea Res. I, 48, 1169-1198, 2001.

Smith, R. S. and Gregory, J. M.: The last glacial cycle: transient simulations with an AOGCM, in press, Clim. Dynam., doi:10.1007/s00382-011-1283-y, www.springerlink.com/ content/a3244p375452q180, 2012.

Smith, R. S., Gregory, J. M., and Osprey, A.: A description of the FAMOUS (version XDBUA) climate model and control run, Geosci. Model Dev., 1, 53-68, doi:10.5194/gmd-1-53-2008, 2008.

Wang, Z., Kuhlbrodt, T., and Meredith, M.: On the response of the Antarctic Circumpolar Current transport to climate change in coupled climate models, J. Geophys. Res., 116, C08011, doi:10.1029/2010JC006757, 2011. 